\title{
El modelo de apertura macroestabilizador: La experiencia de México*
}

René Villarreal**

\section{RESUMEN}

El modelo de apertura macroestabilizador se ha agotado y convertido en una trampa para el crecimiento y la competitividad del país, con bajos coeficientes de inversión y productividad. El modelo macroestabilizador de México en las pasadas dos décadas ha logrado reducir la inflación, que alcanzó más de $150 \%$ en 1987, a niveles de un dígito, pero a costa de un estancamiento económico sin precedentes que ha llevado al país a lo que llamamos el "estancamiento estabilizador", producto de una política macroeconómica iatrogénica (el tratamiento del médico acentúa la enfermedad): política monetaria contraccionista, apreciación cambiaria con sesgo proimportador y una política fiscal con obstáculos estructurales para actuar como política contracíclica.

Palabras clave: modelo macroeconómico, política macroeconómica, estancamiento, competitividad, crecimiento económico, apertura y liberalización comercial, TLCAN.

Número de clasificación JEL: E61, E610.

\section{Abstract}

The Openness Macro-Stabilization Model has been exhausted and converted into the trap to growth and competitiveness of our country, with low investment rate and productivity. The Mexico's Macro-Stabilization Model in the past two decades has succeeded in reducing inflation, which reached over $150 \%$ in 1987, to single digit levels, but at the cost of an unprecedented economic stagnation that has led the country to what we call "stagnation stability" product of an iatrogenic macroeconomic policy (adverse condition in a patient resulting from treatment): contractionary monetary policy, exchange rate appreciation with a pro-importer bias and fiscal policy with structural obstacles to become a countercyclical policy.

Key words: macroeconomic model, macroeconomic policy, stagnation, competitiveness, economic growth, openness and trade liberalization, NAFTA.

Number of classification JEL: E61, E610.

* Ensayo presentado en el seminario internacional "Crecimiento Económico y Desarrollo en América Latina”, Universidad Autónoma Metropolitana, 12-13 de marzo de 2009.

** Doctor en Economía por la Universidad de Yale (1976). Presidente y director general del Centro de Capacitación Intelectual y Competitividad. 


\section{Presentación}

En la década de los años ochenta, México reorientó su modelo de crecimiento, al pasar del modelo de industrialización sustitutiva de importaciones — con fuerte participación del Estado - a un modelo de crecimiento hacia afuera y a la industrialización de exportaciones (IE) buscando el equilibrio externo en sincronía con una industrialización vía el mercado interno. Este cambio de modelo implicaba reformas de carácter estructural, que configuraron el modelo ALPES: apertura, liberalización, privatización y estabilización macroeconómica.

Dentro de este nuevo modelo económico, surgió el modelo de apertura y liberalización comercial vía el TLCAN, como una estrategia regional para elevar la competitividad de América del Norte. Sin embargo, sus efectos se agotaron en la década pasada, ya que México ha perdido liderazgo y posicionamiento en el comercio internacional; China nos ha desplazado en el mercado de EUA, y como región también hemos perdido posicionamiento en el comercio mundial. Así, el modelo que buscaba impulsar el crecimiento vía las exportaciones no ha logrado consolidar la industria exportadora y tampoco su articulación con las cadenas productivas internas.

México ha conseguido controlar las principales variables macroeconómicas que en el pasado representaron una gran carga para el desarrollo económico, como son la inflación (que alcanzó más de $150 \%$ en 1987) y, hasta hace unos meses, el tipo de cambio. Sin embargo, esto no ha conducido a un crecimiento económico sostenido ni sostenible, sino por lo contrario, el costo de la estabilidad ha sido un estancamiento económico sin precedentes que ha llevando al país a lo que llamamos el "estancamiento estabilizador", que se ha convertido en una trampa para el crecimiento.

Así, la pregunta central es: ¿por qué no crecemos si se tiene potencial?, ya que históricamente se han alcanzado tasas de crecimiento de hasta $7 \%$, y en años pasados se registraron grandes excedentes petroleros, entre muchos otros recursos de capital, humanos y financieros con los que cuenta el país.

El presente artículo trata de explicar el modelo de apertura macroestabilizador aplicado en México durante las pasadas décadas, mostrando el agotamiento del modelo exportador y del TLCAN como el camino a la competitividad, así como el freno al crecimiento económico. 


\section{INTRODUCCIÓN}

Si algo ha caracterizado a la política macroeconómica de México durante los ocho años pasados es que ha tenido un objetivo claramente definido: la estabilidad de precios, objetivo que sin duda se ha alcanzado. Sin embargo, lograr este objetivo ha tenido un costo significativo, pues con el propósito decidido e inapelable de alcanzar una inflación semejante a la de nuestro principal socio comercial (tasa promedio de $3 \%$ anual), nos olvidamos de lo más importante: de crecer.

Entre 2001 y 2007 fuimos testigos de una economía caracterizada por baja inflación, la cual promedió $4.3 \%$ anual, pero al mismo tiempo estancada. En este periodo, el producto interno bruto registró un crecimiento promedio de apenas $2.4 \%$, lo que implica un crecimiento del ingreso per cápita inferior a $1.5 \%$ anual. Revisando las cifras de crecimiento de las economías de mayor tamaño en América Latina, Argentina, Brasil, Chile, Colombia, México, Perú y Venezuela, aun sin la crisis económica de por medio, México se enfila a ser la economía de menor crecimiento en la primera década del siglo XXI, dudoso honor que no se había presentado en las cinco décadas pasadas. Más aún, durante 2007 y 2008 incluso Haití, la economía más pobre de la región, creció más que México.

La ausencia de crecimiento económico ha tenido no sólo efectos negativos sobre el bienestar material, sino además consecuencias morales indeseables. Una economía que no crece provoca el desencanto social. En un contexto de crecimiento económico y mejora del bienestar material, cuando la mayoría de la población experimenta mejoría en su nivel de vida, es cuando se incrementan las posibilidades de realizar progresos en aspectos sociales, morales y políticos.

Cuando el crecimiento económico se estanca o cuando hay una declinación en el bienestar material es más probable que haya un ambiente poco propicio para brindar más oportunidades a los más desafortunados, a las personas de bajos ingresos; que la tolerancia y la generosidad disminuyan y que los procesos democráticos se estanquen o retrocedan. Esto se aplica a todo tipo de sociedades, a las de economías avanzadas y emergentes. Cuando la población percibe mejoría en su nivel de vida se crean condiciones propicias para el mejoramiento social, político y moral, también ocurre que cuando las sociedades perciben estancamiento económico y retroceso en su nivel de vida se crean condiciones para el rezago.

Estas consideraciones sin duda son importantes para nuestro país dado el panorama que la economía mexicana ha exhibido en los últimos años. El estan-

camiento económico registrado está creando un ambiente poco propicio para el 
mejoramiento social, político y moral; hay desencanto entre la población, especialmente entre los jóvenes que ven esfumarse sus posibilidades de encontrar empleo bien remunerado, por las escasas oportunidades de mejoramiento. Así, parte de la ciudadanía afirma que preferirían un régimen político menos democrático pero que proveyera mayor bienestar material.

Los malos resultados económicos se manifiestan en desempleo, pobreza y marginación social, informalidad e ilegalidad. Pero esto, a su vez, provoca un gran desánimo entre la población que ve que sus oportunidades de mejoría se van cancelando por la ausencia de crecimiento económico y un ambiente poco propicio para la prosperidad, creando un ambiente de tensión entre los mexicanos y propiciando que algunos, especialmente los jóvenes, prefieran realizar actividades ilícitas en virtud de que sus oportunidades de mejoría se ven muy reducidas si se conducen por el camino de la ley.

La implicación de esto para nuestro país es que el crecimiento económico debería tener una importancia mucho mayor en la agenda de la discusión pública. Nadie duda de la importancia de la estabilidad, pero sólo cuando contribuye al crecimiento económico y no, como en nuestro caso, cuando se convierte en un obstáculo y es parte de una visión ideológica que impide la prosperidad.

\section{EL ENTORNO MUNDIAL}

Dejamos pasar años muy valiosos en los que la economía mexicana pudo crecer más dado el contexto internacional favorable, pero la idolatría a la inflación de un dígito mantuvo a la economía estancada. En las actuales circunstancias de la economía internacional, lo peor, desafortunadamente, está por venir. La situación recesiva de las economías avanzadas y la crisis financiera detonada por el mercado hipotecario de Estados Unidos están profundizando la recesión, han modificado sustancialmente el escenario económico mundial para los próximos años, que ahora luce mucho más sombrío.

Los países de América Latina y el Caribe en un primer momento no se vieron tan afectados por la crisis financiera global, dado que contaban con cierta fortaleza, pero finalmente los efectos en el crecimiento que han llevado a la recesión y estancamiento a muchos países también están afectando a la región. El FMI en sus últimas proyecciones de crecimiento para 2009, estima que América Latina y el Caribe crecerá sólo $1.1 \%$, que aunque es una tasa muy baja sigue siendo superior a los crecimientos negativos de países como EUA, Alemania, España y otras economías desarrolladas. 
Sin duda, la crisis financiera y sus efectos nocivos también han transformado la percepción sobre la función del mercado versus el Estado. La necesidad de una política macroeconómica contracíclica y la pérdida de confianza en los mercados autorregulados han provocado que, después de décadas de franco retroceso en las que principalmente los organismos internacionales y el gobierno de Estados Unidos impulsaron políticas para reducir la función del Estado en la economía, se revalúe la importancia de gobiernos efectivos que puedan intervenir para evitar que las economías se hundan en una profunda recesión que se asemeje a la Gran Depresión de 1929.

Está ocurriendo en la economía mundial lo que hasta hace poco parecía impensable. Uno tras otro, los países desarrollados han anunciado planes de rescate no sólo para las instituciones del sistema financiero sino también para empresas productoras de bienes y servicios, cuya situación ha empeorado drásticamente a consecuencia de la crisis financiera.

\section{Gráfica 1. Expectativas de crecimiento (tasas anuales de crecimiento)}

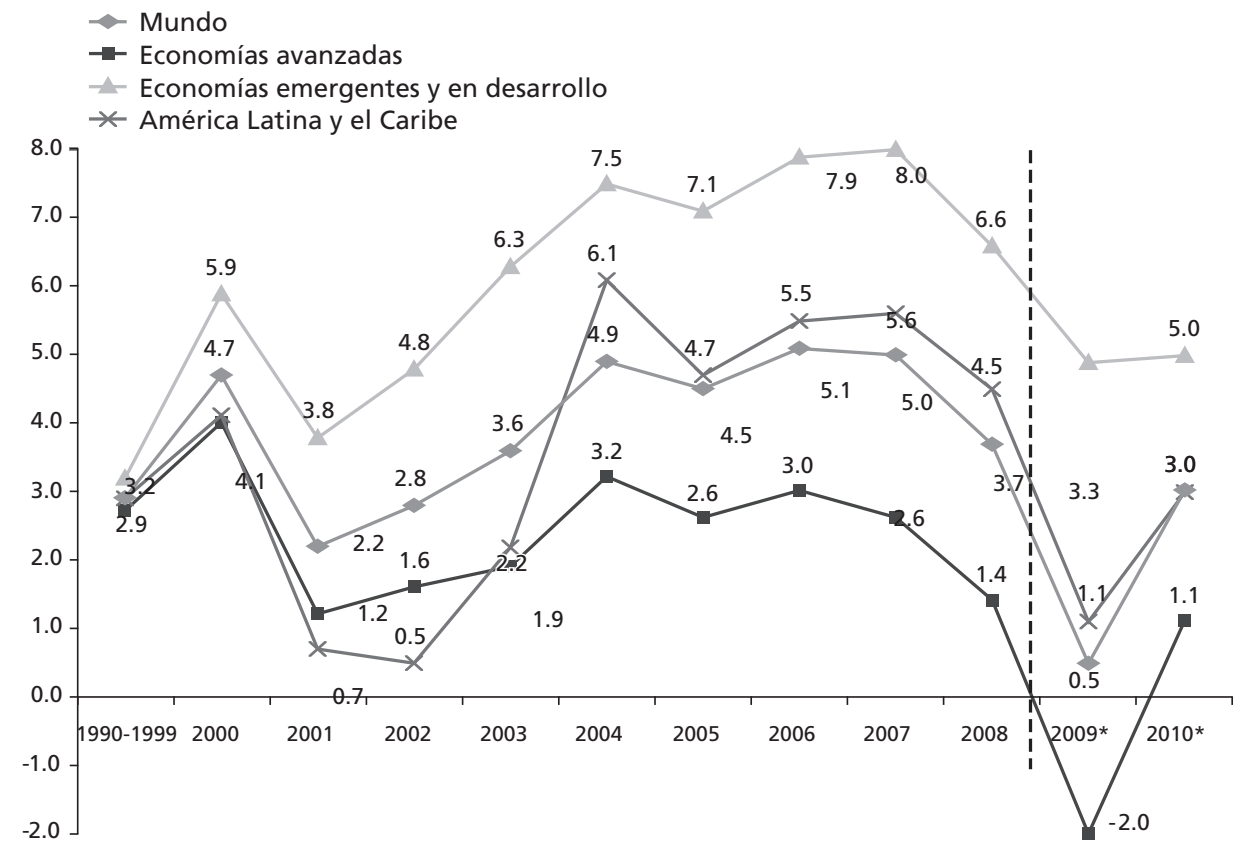

Fuente: FMI, Perspectivas de la economía mundial, octubre de 2008, y Perspectivas de la economía mundial, febrero de 2009. 
En el caso particular de México, las estimaciones de crecimiento para 2009 según el FMI (presentadas a inicio de este año) es que la economía decrecerá $0.3 \%$, y se espera una mejoría leve para 2010 , con una tasa de crecimiento de $2.1 \%$. No obstante, las expectativas del Banco de México son más sombrías, con un crecimiento negativo de cerca de $1.8 \%$, resultado de múltiples factores, entre ellos la caída en la demanda del mercado de EUA, destino de más de $90 \%$ de las exportaciones mexicanas, así como la falta de dinamismo y reactivación del mercado interno.

México cuenta con una economía estable, con una de las inflaciones más bajas en la región latinoamericana. Somos campeones en estabilidad pero ocupamos el último lugar en crecimiento. Se esperaría que como resultado de la crisis financiera internacional actual abandonemos la ideología de libre mercado y retomemos una visión más pragmática y más cercana a la propia teoría económica, que reconozca la importancia tanto del sector privado como del gobierno para alcanzar una economía sólida que crezca a tasas elevadas en forma sostenida, en otras palabras olvidar los paradogmas y enfocarse en acciones que solucionen el problema real del país, la ausencia de crecimiento.

\section{II. ¿QUÉ NOS PASÓ?}

El fenómeno de estancamiento con baja inflación, al que denominamos el estancamiento estabilizador, en contraposición al desarrollo estabilizador de los años sesenta, es resultado de la aplicación del modelo de apertura macroestabilizador que, si bien funcionó como medida de ajuste ante los episodios de hiperinflación y desequilibrio derivados de las crisis recurrentes, ha agotado sus beneficios. Al provocar bajos niveles de competitividad y desindustrialización, se ha convertido en el principal freno al crecimiento, que sumado al creciente desempleo que ha desembocado en informalidad y emigración de nuestros conciudadanos hacia Estados Unidos, desigualdad y pobreza, muestran que el modelo económico es una auténtica trampa para el crecimiento y la competitividad.

La estrategia de crecimiento hacia fuera, el modelo de apertura basado en el dinamismo exportador, con la ausencia de una política industrial de articulación productiva, condujo a un modelo de manufactura de ensamble que provocó la desarticulación de las cadenas productivas y, con ello, que la inversión tuviera un escaso efecto multiplicador sobre la economía nacional. Se confundió el boleto de entrada a la globalización (el TLCAN) con la estrategia del juego, y por ello desapareció la política industrial atendiendo al lema: "la mejor política in- 
dustrial es la que no existe", sin antes implantar una política de competitividad sistémica.

De esta manera, se confundió la necesidad de impulsar el desarrollo competitivo de la industria desechando la vieja política proteccionista con sesgo antiexportador y anticompetitivo, y se pasó al otro extremo, a la ausencia de política de competitividad, de innovación y desarrollo tecnológico, que fomentara las exportaciones, la integración de las cadenas productivas, la competitividad logística e infraestructura, los tecnoparques, y por lo contrario, se cancelaron las políticas e instituciones de fomento, como es el caso del Banco Nacional de Comercio Exterior.

De tal manera que mientras en la segunda parte de los años noventa las exportaciones crecieron a una tasa media anual de casi $17 \%$, producto entre otros aspectos de la entrada en vigor del TLCAN, de la significativa devaluación del peso debido a la crisis de 1994-1995, así como de que no se habían incorporado otros actores importantes al comercio mundial, como China, entre 2001 y 2007 las exportaciones sólo crecieron a una tasa de 5\%, dejando de ser el motor del crecimiento.

El tipo de cambio apreciado y la falta de una estrategia de competitividad sistémica, es decir, la ausencia de una política de competitividad industrial que promoviera la integración y la articulación de las cadenas productivas a lo largo de la cadena de valor, provocaron un sesgo proimportador y finalmente una industrialización de manufactura de ensamble.

Un tipo de cambio apreciado genera una doble carga sobre las exportaciones y los productos nacionales que compiten con las importaciones. Por un lado, las ganancias en productividad de las empresas del país se evaporan con la apreciación cambiaría y, por otro, resulta más barato comprar productos importados; adicionalmente deben padecerse las ineficiencias de la operación interna de la economía. Un tipo de cambio real competitivo es fundamental para el crecimiento en una economía abierta, como lo han demostrado las experiencias de Corea, Taiwán y, recientemente, China.

\section{EL MODELO DE APERTURA Y LIBERALIZACIÓN COMERCIAL A PARTIR DEL TLCAN}

El modelo de apertura y liberalización comercial a partir del TLCAN como estrategia regional para elevar la competitividad de América del Norte se fue agotando con el tiempo y durante la década pasada la región fue perdiendo liderazgo y 
posicionamiento (market share) en el comercio mundial, ya que los tres países que integran el TLCAN han perdido participación de mercado, pasando de $19 \%$ de las exportaciones mundiales a $13.3 \%$. Estados Unidos perdió cerca de cuatro puntos porcentuales, Canadá 1.3 y México poco más de medio punto porcentual.

Sin duda, el gran triunfador ha sido China, que aumentó su participación en el mercado global cinco puntos porcentuales, hasta llegar a una cuota de $9 \%$ de las exportaciones mundiales.

El estancamiento económico y exportador de México en años recientes, ante la velocidad de crecimiento económico, industrial y exportador de China, ha relegado el posicionamiento de México dentro del mercado de Estados Unidos. Las consecuencias de este fenómeno pueden ser mucho más graves para nuestro país de lo que se percibe en la actualidad ya que es creciente el dinamismo en el crecimiento del país asiático.

Aproximadamente $90 \%$ de las exportaciones mexicanas y chinas a los Estados Unidos se centra en 24 capítulos del Sistema Armonizado. En particular, la competencia entre los dos países se localiza en 15 capítulos que comprenden prendas de vestir, muebles, máquinas, aparatos y material eléctrico, y fundición de fierro y acero. Además de los rubros anteriores, la competencia entre China y México se centra en capítulos como diversas manufacturas de metales; productos de piedra, yeso y cemento; equipo de cómputo; manufacturas de fierro y acero, herramientas y artículos de cuchillería; refrigeradores; equipo de cómputo; instrumentos y aparatos de óptica; madera y sus manufacturas, y papel y cartón. Más aún, el traslape entre las exportaciones de China (al mercado de EUA) y las de México se duplicó entre 1990 y 2000 al pasar de 26 a 50\%. Esta tendencia es creciente y se estima que dicho porcentaje se ubicó en más de 60\% en 2007.

En la gráfica 2 se presenta la evolución que han tenido las participaciones relativas de China, Canadá y México a partir de 2000 en el mercado estadounidense. Como se puede observar en el último dato, correspondiente a 2007, China ya superó a Canadá como proveedor en ese mercado, al registrar una participación de $16.46 \%$ del mercado total, por encima de $16.03 \%$ de Canadá y $10.79 \%$ de México, que prácticamente ha estancado su participación en el mercado estadounidense en los últimos años. Es clara la tendencia ascendente de la línea correspondiente a China, mientras que la de Canadá ha disminuido ligeramente aunque de manera sostenida; y la de México permanece casi sin cambio debido a que el crecimiento de las exportaciones es menos vigoroso que antes.

Es así que China rebasó a Canadá para convertirse en el mayor exportador a Estados Unidos, coronando un periodo de seis años en el que sus envíos al 
Gráfica 2. Exportaciones totales de China, Canadá y México al mercado estadounidense, 2000-2007

(Millones de dólares y porcentajes)

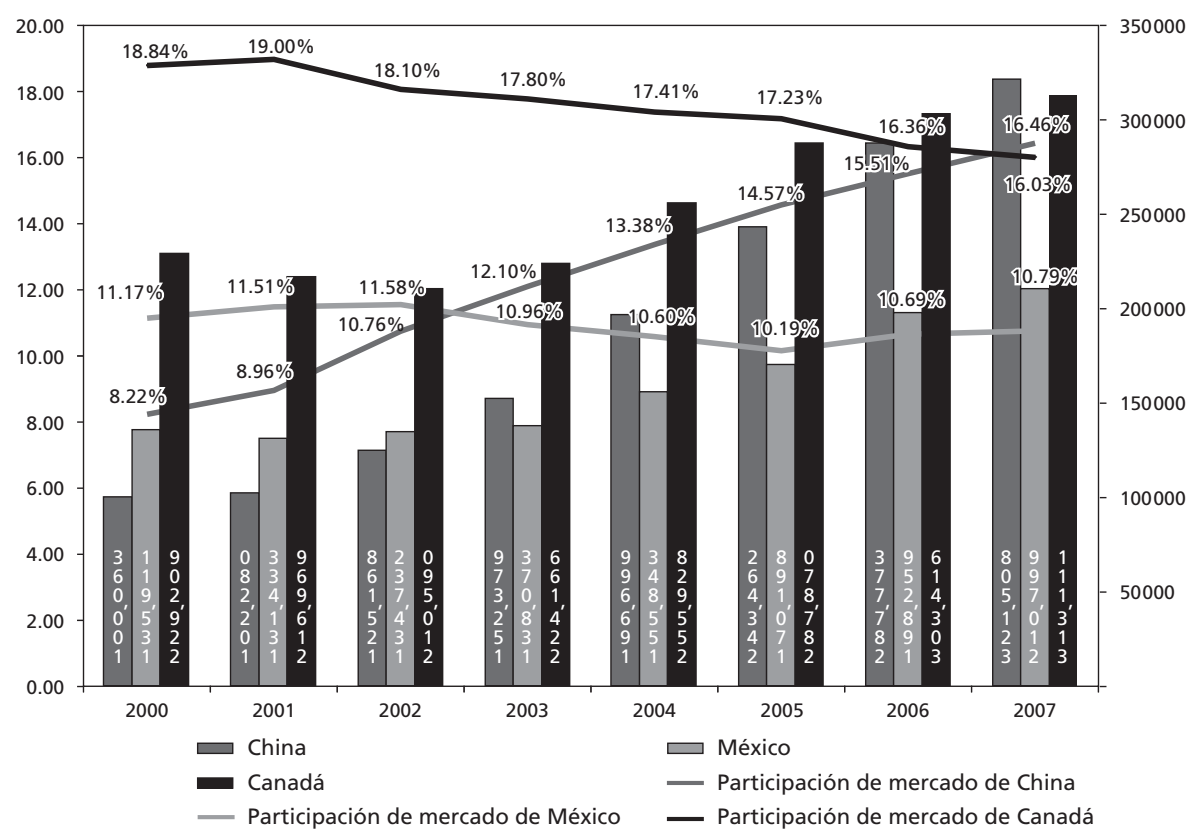

Fuente: Elaborado por CECIC, con datos del Buró de Censos de los Estados Unidos.

mercado estadounidense aumentaron a más del triple. Encabezadas por artículos como televisores de pantalla plana, computadoras, electrodomésticos, juguetes y ropa, las importaciones estadounidenses de productos chinos alcanzaron 321508 millones de dólares en 2007.

China nos desplazó porque cuenta con una estrategia de competitividad basada en polos regionales-clusters, en un marco de crecimiento macroeconómico altamente competitivo y un ambiente de negocios adecuado. Paradójicamente, China, un país comunista, cuenta con un ambiente de negocios para las empresas capitalistas mucho más favorable, rentable y seguro que el existente en los países de América Latina.

México perdió su posicionamiento porque basó su ventaja competitiva en factores temporales y no sustentables, lo cual se manifestó ante la entrada de China como nuevo actor internacional. La fuente de ventaja competitiva sustentable para México ya no puede ser la manufactura de ensamble, la mano de obra barata, las importaciones subsidiadas por un tipo de cambio apreciado -que fo- 
Gráfica 3. Participación de China, Canadá y México como porcentaje del mercado de importación de los Estados Unidos, 2004-2007

(Porcentaje)

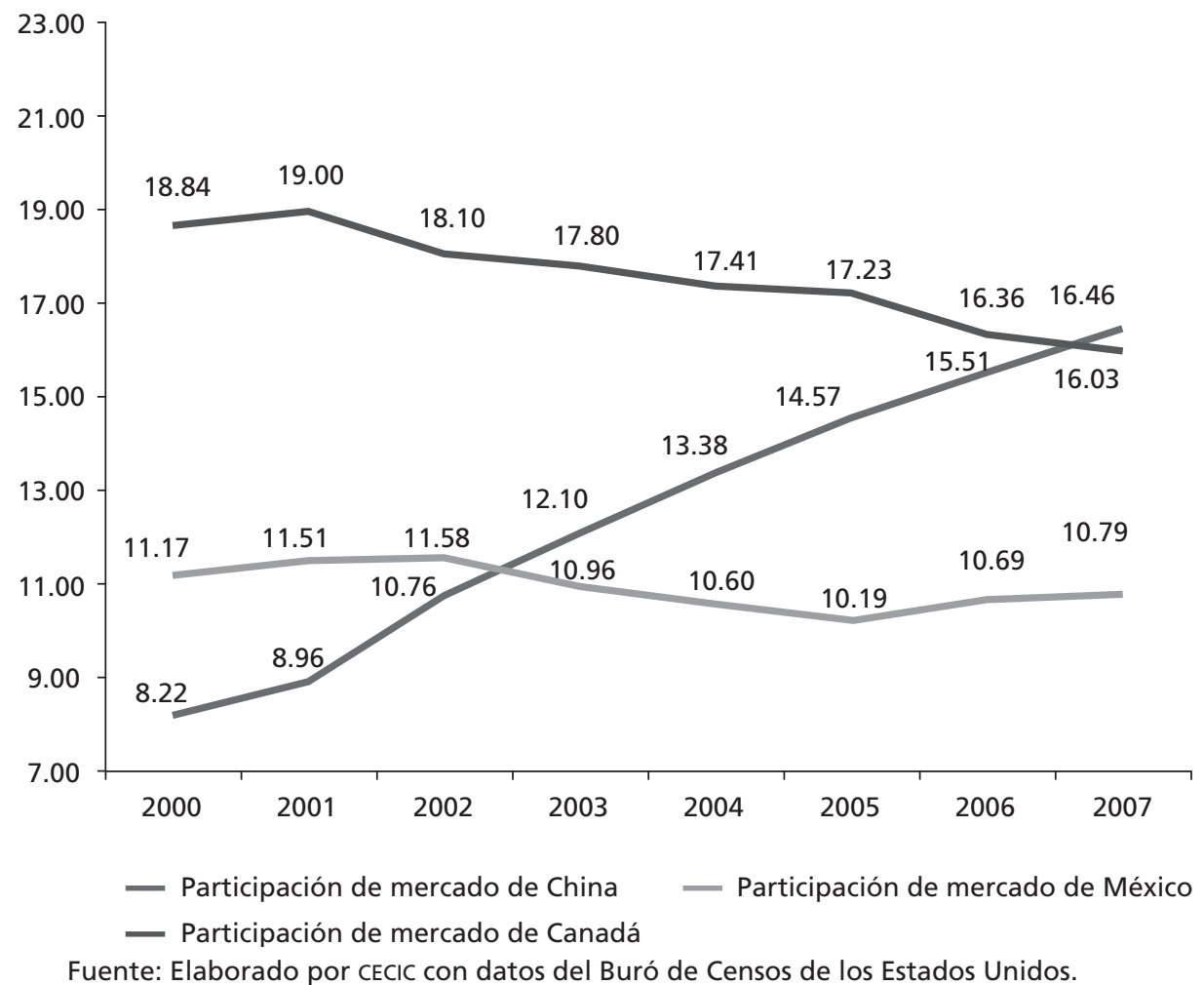

menta la desarticulación productiva-, ni el tener un acuerdo de libre comercio con Estados Unidos. Ahora requerimos un modelo exportador basado en la competitividad sistémica y en nuevas fuentes de ventaja competitiva sustentable fundadas en la mano de obra productiva y en la manufactura de alto valor agregado, esto es, en la innovación.

El libre comercio no es una estrategia de desarrollo. Esto es, no es una estrategia que promueva un crecimiento competitivo y sostenido, y que permita transformar las ventajas competitivas reveladas en ventajas competitivas sustentables, promoviendo un proceso de exportación e industrialización sustentable, y adicionalmente con escalamiento en la cadena global de valor.

Se requiere en paralelo una estrategia de desarrollo que actualmente, en las nuevas economías abiertas a la globalización, es una estrategia de competiti- 
vidad sistémica y una política de competitividad industrial y de los sectores productivos de empresas. Esto es, una estrategia y política de competitividad que eleve las capacidades competitivas pero en el marco de un crecimiento económico que pueda ser sostenido; que promueva la acumulación de capital, el ahorro y la innovación como fuentes fundamentales del crecimiento y en una economía abierta al mundo global. Esto sólo puede alcanzarse si la economía es competitiva; esta es la gran diferencia con el viejo modelo de industrialización sustitutivo de importaciones: antes se podía crecer sin ser competitivo (vía el proteccionismo), actualmente en las economías abiertas a la globalización no se puede crecer, esto es, incrementar la producción y la inversión, y menos sustentar en el mediano y largo plazos un patrón de crecimiento si no hay competitividad sistémica empresas-cluster-gobierno-país.

Los resultados para México, producto de su pertenencia al TLCAN, no son nada alentadores. El modelo exportador tuvo una baja capacidad de arrastre para el resto de la economía nacional, las exportaciones tuvieron un periodo de crecimiento importante, pero actualmente están creciendo a tasas menores a las registradas en la década de los noventa. Además, a pesar de pertenecer al TLCAN, México ha ido perdiendo competitividad mundial. En el mercado estadounidense, China nos desplazó debido a la ineficacia de nuestra estrategia de apertura y de impulso a la exportación de manufacturas de ensamble con la maquila.

La apertura ineficiente generó además un proceso de desindustrialización; la industria ha dejado de ser el motor de crecimiento de la economía. La participación de las manufacturas en el PIB ha ido descendiendo desde 2000, al pasar de 19.8 a $17.7 \%$ en el primer semestre de 2007. La actividad industrial prácticamente se detuvo al promediar en el primer semestre de 2007 un crecimiento anual de solamente $0.7 \%$, mientras que en el mismo periodo del año pasado había mostrado un crecimiento de 5.5\%. Esta situación en 2008 y 2009 fue agravada por los procesos de desaceleración y recesión mundial.

La estrategia de apertura pasiva al exterior vía sólo el TLCAN confundió el boleto de entrada al juego de la hipercompetencia global con la estrategia de juego. México ha carecido de una política de competitividad sistémica y los resultados son evidentes. No se contó con instituciones fuertes que sirvieran de soporte al TLCAN y esto, aunado a la falta de un verdadero financiamiento al desarrollo de la región que permitiera fortalecer la infraestructura y la logística, impidió que el TLCAN incidiera en mayor medida en fortalecer la competitividad de México. 


\section{LA COMPETITIVIDAD DE MÉXICO}

Como muestra de ello tenemos que en el Reporte global de competitividad 20082009 del Foro Económico Mundial, México ocupa el lugar 60 de 134 países, perdiendo ocho lugares respecto al año anterior cuando ocupaba la posición 52, ya que aunque se incrementó el número de países analizados, la mayoría de ellos corresponde a un grado de desarrollo menor al de México.

Como se observa en el cuadro 1, que muestra la posición y calificación de México en cada uno de los 12 pilares que integran esta clasificación, el mejor desempeño del país es en los rubros de tamaño de mercado (11), estabilidad macroeconómica (48) y sofisticación de los negocios (58). Por lo contrario, en temas como mercado laboral (110), instituciones (97) e innovación (90) ocupamos una posición muy baja. Esto es particularmente preocupante debido a que son tres de los pilares más importantes para transitar a la economía del conocimiento.

Cuadro 1. México en el Reporte global de competitividad 2008-2009

\begin{tabular}{|c|c|c|}
\hline & $\begin{array}{c}\text { Lugar } \\
\text { (entre } 134 \text { países) }\end{array}$ & $\begin{array}{c}\text { Calificación } \\
\quad(1-7)\end{array}$ \\
\hline Índice Global de Competitividad (IGC) 2008-2009 & 60 & 4.2 \\
\hline IGC 2007-2008 (entre 131 países) & 52 & 4.3 \\
\hline IGC 2006-2007 (entre 122 países) & 52 & 4.2 \\
\hline Requerimientos básicos & 60 & 4.5 \\
\hline 1er. pilar: Instituciones & 97 & 3.5 \\
\hline $2^{\circ}$. pilar: Infraestructura & 68 & 3.5 \\
\hline 3er. pilar: Estabilidad macroeconómica & 48 & 5.3 \\
\hline $4^{\circ}$. pilar: Salud y educación primaria & 65 & 5.6 \\
\hline Mejoradores de la eficiencia & 55 & 4.2 \\
\hline $5^{\circ}$. pilar: Mayor educación y capacitación & 74 & 3.8 \\
\hline $6^{\circ}$. pilar: Eficiencia del mercado de bienes & 73 & 4.1 \\
\hline $7^{\circ}$. pilar: Eficiencia del mercado laboral & 110 & 4 \\
\hline $8^{\circ}$. pilar: Sofisticación del mercado financiero & 66 & 4.3 \\
\hline $9^{\circ}$. pilar: Aptitud tecnológica & 71 & 3.2 \\
\hline $10^{\circ}$. pilar: Tamaño de mercado & 11 & 5.5 \\
\hline Factores de innovacón y sofisticación & 70 & 3.6 \\
\hline $11^{\circ}$. pilar: Sofisticación de los negocios & 58 & 4.2 \\
\hline $12^{\circ}$. pilar: Innovación & 90 & 2.9 \\
\hline
\end{tabular}

Fuente: Reporte de competitividad global 2008-2009 del Foro Económico Mundial. 
De acuerdo con las etapas de desarrollo de las economías, México se ubica dentro de las llamadas efficiency driven, esto eso en la etapa impulsada por la eficiencia, ya que el desarrollo se basa en la eficiencia de la producción y el incremento de la calidad; sin embargo, es necesario transitar a la etapa impulsada por la innovación, que es donde se desarrolla la economía del conocimiento con mayor productividad, y por tanto, mejores sueldos.

Por otra parte, la diversidad de la estructura productiva es uno de los factores en los que México mejoró su posición competitiva, lo cual se refleja en las calificaciones satisfactorias en términos de refinamiento de los negocios (58). A pesar de estas fortalezas, México no ha podido explotar todo su potencial y se ubica todavía por debajo de otras economías emergentes, como China (30), India (50) o la Federación Rusa (51). La inseguridad, la rigidez del mercado laboral, una burocracia ineficiente, la baja calidad de la educación y la presencia de prácticas anticompetitivas son los principales factores que inciden negativamente sobre la competitividad de México.

En materia del costo que representa para los negocios el crimen y la violencia, México se ubica en la posición 125, lo que además de ubicarlo casi al final de la tabla representa una caída de seis lugares respecto al año pasado, cuando ocupó el lugar 119. En lo referente al crimen organizado, tiene el lugar 127 frente al 120 del reporte anterior; en confiabilidad de los servicios policiacos, en el lugar 124, y en eficiencia del marco legal en la posición 111, lo cual es un claro reflejo de la grave crisis de inseguridad que enfrenta nuestro país. Otro gran obstáculo para la competitividad de México es la calidad del sistema educativo. Así, en este indicador, nuestro país se ubica en el lugar 109; en calidad de la educación en ciencia y matemáticas, en el 127; en el 116 en calidad de la educación primaria y en el 105 en disponibilidad de científicos e ingenieros.

Finalmente, en el análisis sobre los factores que los empresarios consideran más problemáticos para hacer negocios, en el caso de México destaca que $18.4 \%$ considera que la ineficiencia gubernamental y la burocracia son el factor más limitante, seguido de la corrupción (13.1\%), infraestructura inadecuada $(10.3 \%)$ y la regulación laboral restrictiva $(10 \%)$. Es por ello que aún es necesario realizar grandes esfuerzos por mejorar la seguridad de los individuos y las empresas, desarrollar un gobierno moderno, inteligente y ágil; así como continuar con las acciones encaminadas a mejorar las condiciones para mejorar el acceso al financiamiento.

De manera paralela a este modelo de apertura pasiva, se implantó un modelo macroestabilizador que se convirtió en una trampa para el crecimiento. 
Gráfica 4. Factores problemáticos para hacer negocios

(Porcentaje de respuestas)

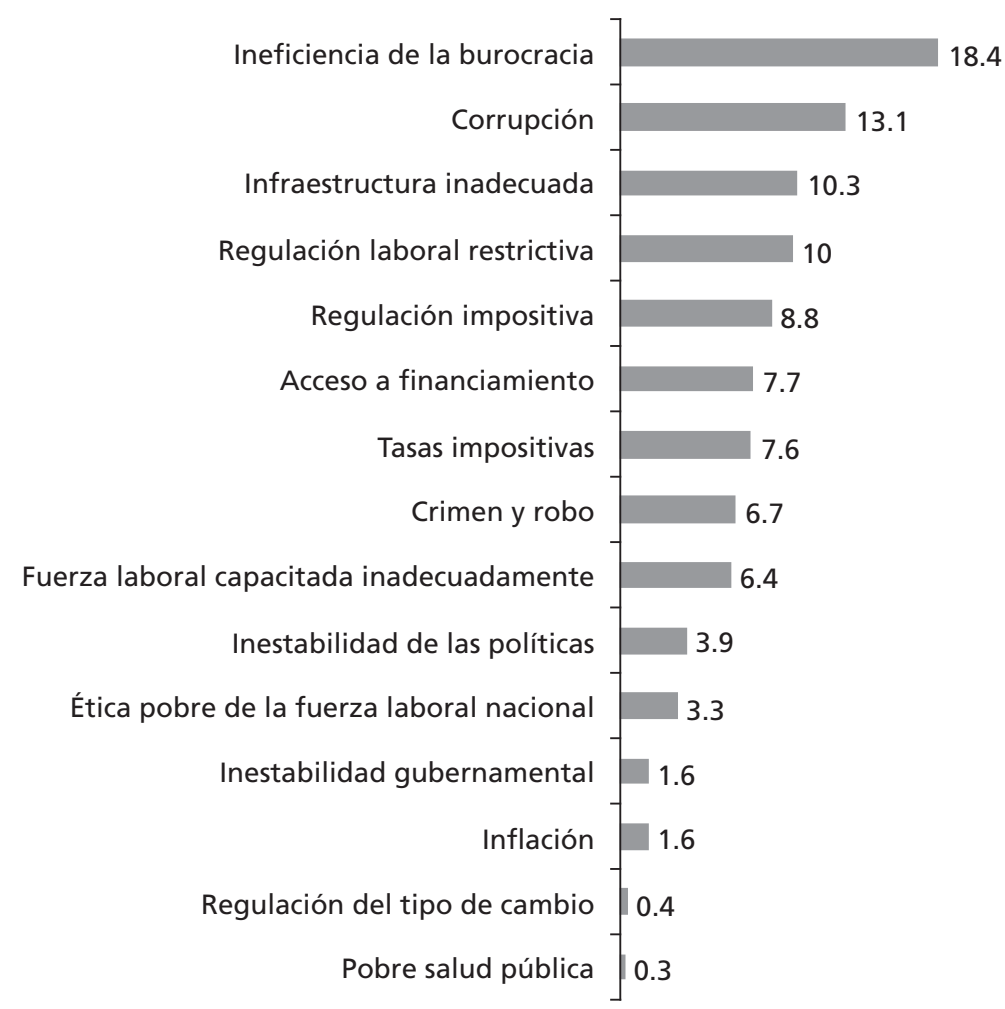

Fuente: Reporte de competitividad global 2008-2009 del Foro Económico Mundial.

Como resultado de esta estrategia, México entró en una fase de estancamiento estabilizador que si bien mantuvo la inflación en niveles bajos (de alrededor de $4 \%$ ) al mismo tiempo se convirtió en un freno de mano para la economía, impidiendo que ésta pudiera crecer a su potencial de pleno empleo.

El modelo de apertura macroestabilizador no permitió desarrollar un entorno favorable a los negocios debido a que no se pudo generar un crecimiento competitivo sostenido. Esto obedece a que la política macroeconómica ha sido unidimensional, es decir, se ha centrado en la inflación, dejando de lado otras dimensiones que conforman la política macroeconómica de crecimiento, como el desarrollo y fortalecimiento del mercado interno, además del balance interno, a partir de la estabilidad de precios, y el externo, con el equilibro en la balanza de pagos. Además, se confundió la autonomía del banco central con la independen- 
cia de la política económica. Que el Banco de México sea autónomo no significa que la política macroeconómica tenga que subordinarse a su único objetivo: la inflación.

Las ineficiencias generadas por el modelo de apertura macroestabilizadora dieron como resultado un periodo de estancamiento estabilizador, en el que se generó una amplia brecha entre el producto real y el producto potencial.

La fragilidad estructural del dinamismo exportador de la economía mexicana está sujeta invariablemente a los vaivenes de la economía estadounidense y, ante todo, a los avatares de una ventaja comparativa estática y de corto plazo, como es el caso de la mano de obra barata. Aun cuando a partir de los años noventa la maquila se consolidó como el centro del modelo exportador mexicano en razón del crecimiento observado en términos de ocupación y producción, experimentó un cierto retraimiento desde finales de 2000 debido al descenso de la demanda estadounidense y a la competencia de países con salarios más bajos que México, como China, que propiciaron la reubicación de las maquiladoras y el crecimiento relativo de los salarios en las maquiladoras instaladas en México.

Por ello, México requiere olvidar el falso dilema de crecimiento hacia afuera versus crecimiento hacia adentro y pasar a una estrategia de crecimiento equilibrado, apoyándose en los motores externo e interno.

La política económica de macroestabilización tiene el grave defecto de tener como único objetivo la estabilidad de precios, con todos los instrumentos dirigidos a lograrlo: política fiscal de equilibrio presupuestal (basada en una inversión pública limitada y no en una mayor recaudación), política cambiaria que considera el tipo de cambio como una ancla deflacionaria (que ha terminado por apreciarlo en términos reales), y política monetaria no sólo restrictiva sino astringente.

Este manejo de la política macroeconómica, que consiste en dirigir todos los instrumentos hacia un solo objetivo, tiene utilidad cuando se trata de atacar la hiperinflación; sin embargo, cuando ya se alcanzó el objetivo de inflación moderada y se continúa con la misma política, ésta se convierte en un fenómeno que en medicina se conoce como iatrogenia, es decir, cuando el médico, el tratamiento o el medicamento agrava la enfermedad del paciente. En el caso mexicano, dirigir los instrumentos de política económica hacia el —obsesivo- objetivo de abatir o, más bien, no permitir que repunte la inflación, ha terminado por frenar y finalmente estancar la economía y, como veremos, por desarticular el tejido productivo y deteriorar el tejido social. Cabe entonces decir que México es una economía grave pero estable. 


\section{EL CRECIMIENTO ECONÓMICO DE MÉXICO Y LA EVOLUCIÓN DE LAS PRINCIPALES VARIABLES MACROECONÓMICAS}

Durante el periodo 1977-1981, México entró en una etapa en la cual el petróleo funcionó como el pivote de la economía nacional, y de la sustitución de importaciones se pasó a una economía monoexportadora. Durante este periodo, el PIB real creció a una tasa de $8 \%$, pero la inflación promedio se elevó a casi $24 \%$. Asimismo, las finanzas públicas se deterioraron considerablemente y debido a la fuerte dependencia de los ingresos públicos de las exportaciones petroleras, la caída del precio del crudo provocó efectos devastadores en el país. En 1982 se presentó en México la crisis de la deuda externa y en ese año el país fue marginado de los mercados internacionales de capitales.

El agotamiento del modelo de sustitución de importaciones en 1976 significó el inicio de la crisis estructural que entre 1982 y 1987 alcanzó su clímax.

Gráfica 5. Las etapas en el crecimiento económico de México, 1982-2007

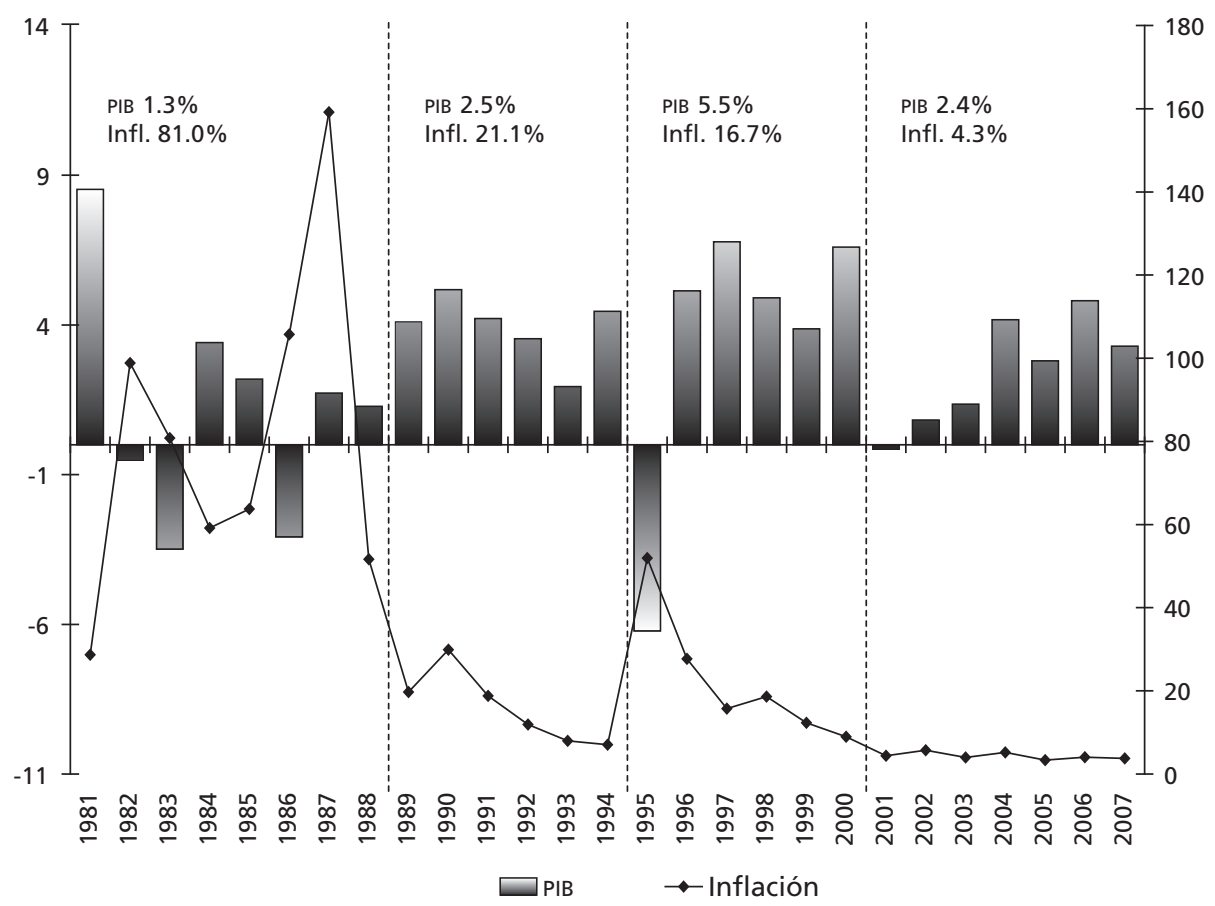

Fuente: INEGI y Banco de México. 
Este periodo se caracterizó por un ajuste prolongado, con procesos de alto y siga, pero en donde la etapa recesiva fue la predominante; a este contexto se sumó el choque petrolero externo de 1986 y la fuga de capitales de 1987. En noviembre de 1987, el Banco de México se retiró del mercado cambiario, devaluándose el tipo de cambio libre en dos ocasiones hasta alcanzar 41\% (2400 pesos por dólar). El lunes 14 de diciembre se devaluó $18 \%$ el tipo de cambio controlado. Durante este periodo, la inflación promedio anual fue de 95\% y el PIB creció apenas $0.08 \%$. Ante la situación en el mercado cambiario, las fuertes presiones inflacionarias y el contexto de bajo crecimiento del PIB, se decidió aplicar, en diciembre de 1987, un programa de ajuste en el que la evolución del tipo de cambio y la política de ingresos serían decisivas. Los pactos de estabilización hicieron su aparición y, con ellos, se buscó controlar la inflación.

Durante este periodo, el régimen de tipo de cambio prevaleciente puede caracterizarse como semifijo, con propósitos de reducir la inflación a partir de su utilización como ancla de los precios. Se pensó que era más fácil controlar un solo precio (el del dólar), que todos los precios. A partir de 1988, la estabilidad de precios pasó a ser el objetivo número uno de la política económica; y dicho objetivo sigue en pie actualmente aunque durante la crisis de 1994-1995 su cumplimiento se "interrumpió".

El periodo correspondiente a los años 1981-1988 se caracterizó por el estancamiento económico con equilibrio externo e inflación. Durante estos años se presentó la crisis de la deuda externa (1982) y la posterior marginación de México de los mercados internacionales de capital a causa de la pérdida de confianza de inversionistas internacionales; también se emprendieron importantes acciones en materia de apertura comercial y liberalización financiera, destacando la entrada de México al GATT; asimismo, se redefinió la función del Estado en la economía, reduciéndose su participación e iniciándose un proceso de privatización de empresas públicas. La tasa media de crecimiento económico de este periodo fue muy baja (1.3\%), la inflación promedio fue de $81 \%$ y la balanza en cuenta corriente se mantuvo prácticamente en equilibrio, gracias a la política devaluatoria utilizada para fomentar las exportaciones y obtener las divisas que la economía requería para cumplir con sus obligaciones en el exterior.

Durante el periodo 1989-1995, el reto que se tuvo desde el inicio del sexenio fue paliar los efectos negativos y nocivos de una elevada inflación, así como la inercia inflacionaria que se había alcanzado tras utilizar reiteradamente al tipo de cambio activamente. 
Esto se logró a partir de la política de los pactos de estabilización en los que, nuevamente, se utilizó el tipo de cambio y los controles de precios y salarios como anclas deflacionarias. Asimismo, en este periodo se intensificaron los procesos de reforma estructural, apertura comercial y financiera, además del proceso de privatizaciones, y se logró una renegociación exitosa de la deuda externa (Plan Brady de 1989). Este periodo se caracterizó por las fuertes entradas de capital externo aunque en su mayoría de corto plazo, sobre todo en 1991-1993, que provocaron indirectamente el deterioro de la competitividad de las exportaciones mediante la apreciación del tipo de cambio real. Así, a partir de 1992 se manifestaron diversos problemas, indicativos de lo que posteriormente sería la crisis externa más grave de la historia moderna de México (1994-1995).

El crecimiento financiado principalmente con recursos externos de corto plazo, sin un incremento en el ahorro interno, así como un sector productivo interno inmaduro, orientado al mercado externo y con débil integración con las cadenas productivas, produjeron la crisis de 1994-1995. Así, este periodo (1989$1995)$ estuvo caracterizado por un crecimiento moderado (2.5\%), una inflación de $21.1 \%$ y un desequilibrio externo creciente, que para 1994 llegó a 30 mil millones de dólares y representó 6.5\% del PIB (déficit en la balanza de cuenta corriente).

Durante la tercera etapa del periodo considerado en esta sección, caracterizada por el retorno de una considerable inflación, fuga de capitales, crecimiento significativo de las tasas de interés y crisis del sistema bancario mexicano, el principal reto del gobierno entrante fue rescatar al sistema bancario, la recuperación económica y el abatimiento de la inflación. La salida de capitales iniciada desde diciembre de 1994 produjo efectos nocivos en la economía mexicana, en términos de crecimiento económico, consumo, inversión y salarios reales. En particular, la fuga de capitales generó importantes presiones sobre el tipo de cambio dada la pérdida abrupta de reservas internacionales y la imposibilidad para las autoridades monetarias de sostener el techo de la banda cambiaria, lo que llevó a una devaluación del tipo de cambio de 100\% (de 3.5 a 7 pesos por dólar) y una inflación de 55\% para 1995.

Después de las turbulencias de la crisis de 1994-1995, el Banco de México y la Comisión de Cambios decidieron aplicar la flotación administrada, combinada con un objetivo de inflación establecido de antemano (inflation targeting). Esta combinación de políticas permitió que el banco central ganara independencia y pudiera influir favorablemente en la reducción del traspaso (pass through) del tipo de cambio a la inflación. El banco central estableció un objetivo de infla- 
ción dado a conocer de antemano y pudo intervenir en el mercado cambiario siempre que los movimientos del tipo de cambio entraran en conflicto con el cumplimiento de dicho objetivo. De esta manera la política de estabilización tiene como único objetivo mantener la inflación bajo control, sin importar los costos: el estancamiento de la economía, la pérdida de competitividad y el malestar social.

El periodo 2001-2008 se caracterizó por un bajo crecimiento económico, baja inflación, un déficit moderado en cuenta corriente y elevado desempleo. En promedio, el crecimiento del PIB fue inferior a $2 \%$, la inflación cercana a $5 \%$, el déficit externo menor a $2 \%$ del PIB y la tasa de desocupación de $3.4 \%$.

\section{EL MODELO MACROESTABILIZADOR}

Las perspectivas para el futuro cercano, en términos de crecimiento económico, no son muy alentadoras. Como consecuencia de la adversa situación económica internacional, una de las estimaciones más recientes del Banco de México es que se espera una tasa de crecimiento negativa entre -0.8 y $-1.8 \%$ en 2009. Las política monetaria y fiscal difícilmente podrán revertir esta tendencia: el programa económico anticíclico anunciado por el gobierno federal no compromete recursos suficientes y la política monetaria continúa buscando una menor inflación sin ocuparse del crecimiento y el empleo.

La situación se agrava por las dificultades que atraviesa la economía de Estados Unidos, que se han agudizado como producto de la crisis financiera. La contracción del crédito que está ocurriendo en ese país y en otros puede provocar una recesión más profunda que la prevista hasta ahora.

Cuadro 2. Evolución de las principales variables macro por periodos, 1981-2007

(Porcentaje)

\begin{tabular}{llc} 
& PIB & Inflación \\
\hline $1981-1988$ & 1.3 & 81.0 \\
$1989-1995$ & 2.5 & 21.1 \\
$1996-2000$ & 5.5 & 16.7 \\
$2001-2007$ & 2.4 & 4.3 \\
\hline
\end{tabular}

Fuente: INEGI y Banco de México.

El modelo macroestabilizador de México en las dos décadas pasadas ha logrado reducir la inflación que llegó a alcanzar más de 150\% en 1987, y pasó a 
niveles de un dígito en los años recientes, pero a costa de un estancamiento económico sin precedentes que ha llevado al país al estancamiento estabilizador, en contraste con el desarrollo estabilizador de los años sesenta, cuando la economía crecía a una tasa promedio anual de $6.8 \%$, con una inflación de $3 \%$ anual y estabilidad cambiaria. La política macroeconómica iatrogénica es responsable del modelo de estancamiento estabilizador: política monetaria contraccionista, apreciación cambiaria con sesgo proimportador y una política fiscal con obstáculos estructurales que le impiden actuar como política contracíclica. Así, la política macroeconómica unidimensional, cuyo único objetivo es la inflación, se ha convertido en una verdadera trampa para el crecimiento, la generación de empleos y la competitividad de México.

El estancamiento estabilizador se ha convertido en la trampa para el crecimiento económico de México. Este estancamiento es el resultado de la aplicación del modelo de estabilización, de privilegiar el combate a la inflación antes que el crecimiento económico. Esto, si bien funciona como medida de ajuste ante episodios de hiperinflación, resulta anacrónico para enfrentar los retos que se presentan actualmente. Es urgente que México retome la senda del crecimiento competitivo y sustentable.

Al aplicar este modelo, se pierde de vista que el arte del manejo macroeconómico consiste en cómo hacer crecer el PIB potencial, es decir, utilizando plenamente los recursos de capital y trabajo (pleno empleo) disponibles, con equilibrio interno y externo. Así, México ha caído en un estancamiento estabilizador anticompetitivo que se ha evidenciado en la última década de manera más clara; la economía mexicana es de las más abiertas y de las menos competitivas y el modelo exportador se ha agotado como motor del crecimiento, y la inflación se ha convertido en el objetivo prioritario y prácticamente único de la política económica, orientándose todos los instrumentos disponibles a lograrlo. Así, la economía está estable, con una inflación de un dígito, pero está también parada, no crece.

Al priorizar la estabilidad de precios como objetivo único, se aplica una camisa de fuerza a la economía mexicana que le impide crecer. Tenemos una locomotora que puede avanzar a 100 kilómetros por hora, pero que lo hace a 40 porque trae el freno de mano puesto. Peor aún, la mitad de los mexicanos que deberían viajar en la locomotora ni siquiera van en el último vagón, se han quedado abajo y con el tiempo, si su situación económica no mejora, pueden hacer que los que van arriba también tengan que bajarse.

Mucho se ha escrito sobre la importancia de las reformas estructurales y del papel que podrían jugar en el desempeño económico de México, pero la pri- 


\section{Gráfica 6. Crecimiento real del PIB vs. crecimiento potencial* (Miles de millones de pesos a precios de 1993)}

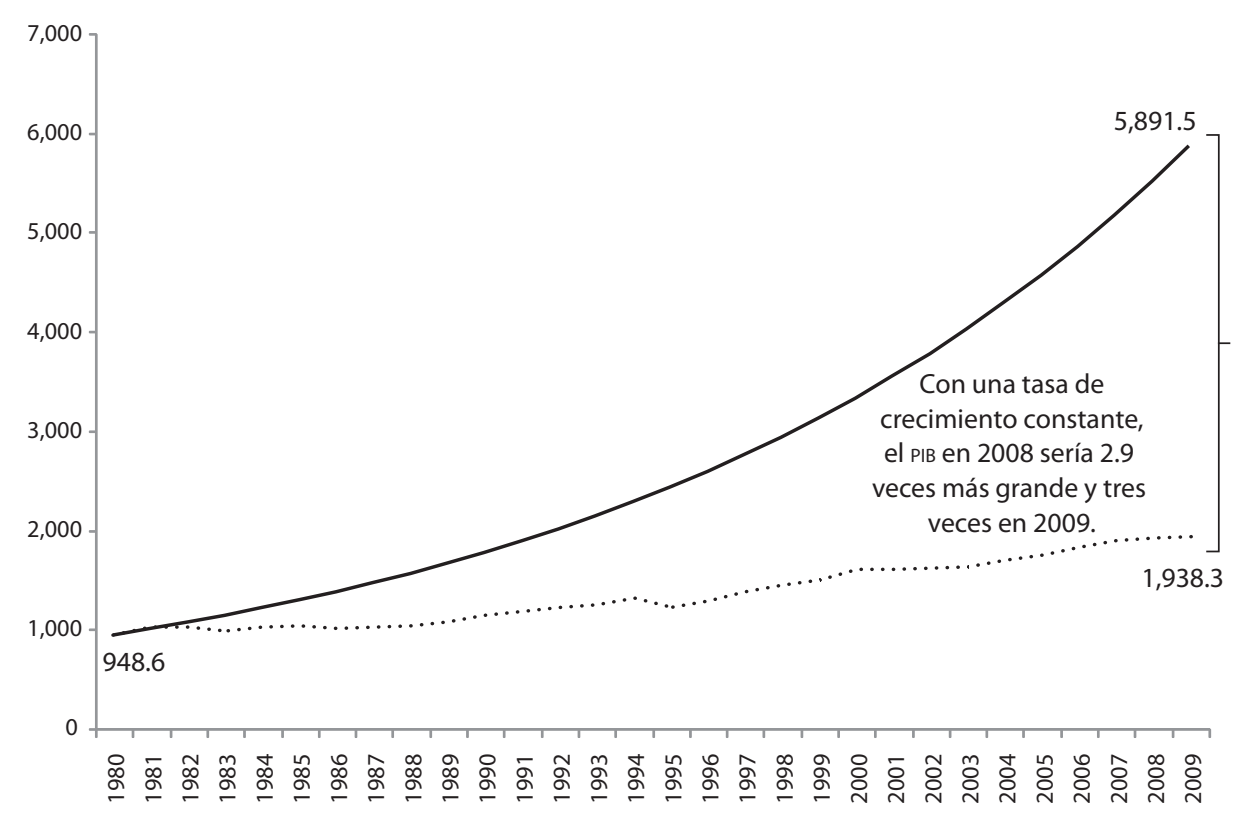

* Este es un ejercicio de cálculo de la evolución del PIB bajo el supuesto de que el PIB hubiera crecido a una tasa de $6.5 \%$ anual desde 1980. Los PIB de 2008 y 2009 son con base en los cierres esperados, según la Encuesta de Banxico sobre expectativas de los especialistas en economía del sector privado a noviembre de 2008.

Fuente: Elaboración propia con base en datos del INEGI.

mera reforma que debería plantearse es la referente al artículo 28 de la Constitución y a la Ley del Banco de México para que éste, además de la estabilidad del poder adquisitivo del peso, tenga como mandato también el crecimiento económico. La autonomía del banco central no debe confundirse con independencia de la política económica; la autonomía debería limitarse al hecho de que el banco central no esté obligado a financiar los déficit del sector público, y a la responsabilidad en el manejo de la política monetaria (tasa de interés y crédito), pero en coordinación y armonía con el resto de la política macroeconómica (política fiscal y cambiaria) y con ambos objetivos: estabilidad de precios y crecimiento.

En la reforma a la Ley del Banco de México y al artículo 28 de la Constitución deben establecerse los mecanismos de coordinación para que la actuación del banco central se enmarque dentro de la política económica que defina el gobierno federal, de forma que atienda las prioridades que sobre los objetivos 
definan el Congreso de la Unión y el Poder Ejecutivo Federal. Sin duda, es esencial que exista coordinación institucional en la definición de la política monetaria y cambiaria. Por ejemplo, el Banco de México no tiene por qué fijar unilateralmente el objetivo de inflación, el cual debería determinar el programa macroeconómico del gobierno federal (documento de Criterios de Política Macroeconómica) que se presenta y se aprueba también por el Congreso de la Unión.

La reforma también debe contemplar que el Banco de México, al igual que el Banco de la Reserva Federal en Estados Unidos, atienda simultáneamente dos objetivos: el crecimiento y la estabilidad de precios.

Aparte de reconocer que existen otros objetivos fundamentales, es muy importante que la reforma incorpore criterios de eficacia y eficiencia, puesto que actualmente nadie le pide cuentas al Banco de México sobre el costo económico que ha tenido el mantener como objetivo único la estabilidad de los precios. Tal parece que sólo necesita cumplir con la estabilidad de precios, independientemente del costo al que se consiga. El trade-off que ocurre entre inflación y crecimiento no ha estado presente dentro de los criterios con los que se ha regido el Banxico, por lo que la política monetaria y cambiaria que ha seguido el banco central no se ha evaluado en términos del costo económico que significa no crecer al ritmo del PIB potencial.

El costo de la ineficiencia macroeconómica se refleja en que si el país hubiese crecido a la tasa potencial (6.5\%) en los últimos 27 años (1980-2007), el tamaño del PIB de México en 2007 hubiera sido de casi el triple (2.65 veces) de lo que fue y alrededor de cinco veces el de 1980. Lo que le hubiera permitido a México ubicarse en el séptimo lugar, dado el tamaño de su economía, mundial.

El problema central de la falta de coordinación no son las personas, sino la forma en que se definió la autonomía del Banco de México. Es un problema interinstitucional que rebasa a las personas que dirigen los rumbos del país y del banco central. Esto se evidenció en 2008, con el planteamiento público del presidente Felipe Calderón para que Banxico no aumentara sus tasas de interés más allá de lo necesario, dada la afectación que esto produciría en el crecimiento económico. El presidente realizó su petición, con toda razón, porque había ofrecido crear un millón de empleos anualmente, mientras que el Banco de México ya estaba anunciando que sólo se crearían 370 mil en 2008.

Felipe Calderón instó al Banxico para que no aumentara la tasa de referencia argumentando que la inflación era principalmente de origen importado, por lo que no se requería de un ajuste monetario. Por ello, es indispensable que las diferentes autoridades económicas del país trabajen de manera coordinada 
bajo los lineamientos de la cabeza del sector económico, la Secretaría de Hacienda, que ha intentado poner en marcha un programa anticíclico para enfrentar la recesión internacional, en particular la de Estados Unidos, pero la falta de coordinación interinstitucional ha funcionado como freno a este programa. Por ejemplo, el Fondo Nacional de Infraestructura no ha podido ejercer el gasto asignado por la lentitud y retraso en las licitaciones y fallos de la obra pública.

Por otra parte, hoy en día el problema de la inseguridad es el que se percibe como la mayor preocupación de la sociedad e inclusive se refleja en la economía, ya que la inseguridad desencadena una menor inversión y costos más altos para las empresas. El secretario de Hacienda, Agustín Carstens, señaló recientemente que la inseguridad le cuesta al país alrededor de un punto porcentual del PIB. En este señalamiento de las autoridades económicas se deja ver que pretenden presentar la falta de crecimiento económico como una consecuencia de la delincuencia, cuando el origen de ésta se encuentra precisamente en la falta de un crecimiento económico sostenido que hubiera permitido cerrar la brecha de la desigualdad.

Para superar el estancamiento estabilizador es necesario pasar a un modelo macro tridimensional con tres objetivos: crecimiento competitivo con equilibrio interno (estabilidad de precios) y externo (déficit de cuenta corriente financiable). Este es el verdadero arte del management o gestión de la política macroeconómica, crecer a pleno empleo con estabilidad interna y externa. No representa ningún reto estabilizar una economía estancada; el reto es crecer a capacidad plena (crecimiento del producto de 6-7\%) con estabilidad.

El estancamiento ha provocado bajos niveles de competitividad y ha hecho caer a México en la desindustrialización, y el modelo macroestabilizador se ha convertido en el principal freno al crecimiento; si además se añade el creciente desempleo que ha desembocado en informalidad y emigración, desigualdad y pobreza, el modelo económico es una auténtica trampa para el desarrollo productivo de la economía mexicana, y lo peor es que se ha vuelto crónico. Este mal crónico de la economía mexicana genera destrucción del tejido social y un desencanto generalizado en la población, con la consecuente incidencia sobre el crimen y la delincuencia.

La apertura y la estabilización macroeconómica no han sido suficientes - aun cuando fueron necesarias - para generar un crecimiento competitivo sustentable; tampoco lo fueron para establecer un modelo de industrialización exportador con capacidad de arrastre interno vía articulación de las cadenas productivas y para enfrentar y reducir las cuatro brechas del desarrollo: crecimiento, competitividad, empleo y equidad. 
La brecha del crecimiento refleja el diferencial entre el crecimiento real y el potencial que pueden alcanzar las economías en una situación de pleno empleo. Si el crecimiento potencial para México es de $6.5 \%$ del PIB y la tasa promedio de crecimiento en el último sexenio fue de $2.3 \%$, la brecha a cerrar es de $4.2 \%$ del PIB para lograr un uso pleno de los recursos de la economía mexicana.

La brecha de la competitividad se refleja en el hecho de que México ocupa el lugar 60 de 134 países en competitividad internacional de acuerdo con el Foro Económico Mundial, pero se ubica en el lugar número 15 de acuerdo con el tamaño del PIB según el Banco Mundial, por lo que existe una brecha de 45 lugares en lo que debería ser su posicionamiento competitivo frente a los demás países.

La brecha del empleo productivo equivale al número de empleos que se están dejando de generar en el mercado formal. El desempleo abierto en México entre 2001 y 2006 fue relativamente bajo (3.1\%). En el sexenio anterior, según cifras del IMSS, se generaron un promedio de 236500 nuevos puestos de trabajo anuales, de los cuales únicamente $35 \%$ fueron permanentes. Si debido a las variaciones en la PEA se incorporaron anualmente un promedio de 755 mil personas al mercado laboral entre 2001 y 2006, el déficit de empleos fue de 519 mil anuales.

La brecha de la equidad equivale al porcentaje de la población que vive en condiciones de pobreza. De acuerdo con los tres tipos de pobreza que se miden cada dos años, entre 2000 y 2006 la pobreza alimentaria pasó de $24.1 \%$ a $13.8 \%$, la de capacidades se redujo de 31.8 a $20.7 \%$ y la de patrimonio pasó de 53.6 a $42.6 \%$. Así, aunque en el sexenio anterior se dieron algunos avances en el combate a la pobreza, el reto es crecer de manera sostenida, cerrando la brecha de la pobreza, y el mejor camino y política económico-social es crear empleos productivos y bien remunerados para que la población pueda adquirir con sus ingresos propios los satisfactores básicos para el desarrollo humano.

Como se ha expuesto a lo largo del presente documento, cuando la economía atraviesa por episodios macroeconómicos con grandes perturbaciones, se justifica que todos los instrumentos de política económica se orienten al único fin de solucionar dicha perturbación. No obstante, en condiciones macroeconómicas normales el gran objetivo debe ser el crecimiento económico competitivo, con estabilidad interna y equilibrio externo, para lo cual se deben asignar instrumentos diferenciados para el logro del crecimiento económico, la estabilidad interna (inflación) y el equilibrio externo (déficit externo financiable).

En términos macroeconómicos, la política fiscal se suele orientar al fomento de la inversión y el crecimiento económico; la política cambiaria al logro 
del equilibrio externo y la política monetaria a la estabilización macroeconómica. No obstante, en el caso del estancamiento estabilizador de México se observa que el objetivo de la estabilización macroeconómica se ha superpuesto a los objetivos del crecimiento económico y se mantiene un desequilibrio externo del orden de $1 \%$ del PIB, no por el buen manejo cambiario sino porque la economía no crece.

Cuando en 1987 se alcanzó un nivel de inflación mayor de 150\% era incuestionable dicha orientación unidimensional, pues nos encontrábamos en un escenario hiperinflacionario para México, pero una vez que la economía alcanzó niveles de inflación de un dígito, nuevamente el objetivo debería ser el crecimiento económico competitivo con equilibrio externo y estabilidad macroeconómica.

En una economía en la que ya se ha logrado la estabilización macroeconómica (inflación de un dígito), el gran reto consiste en reactivar y consolidar el crecimiento económico en el mediano y largo plazos de manera competitiva, con equilibrio interno y externo y generando empleos de calidad.

Es importante reconocer la importancia que tiene el mantener bajos niveles de inflación, pero no debemos hacer de la estabilización de precios el fin último y supremo de la política económica. El control de la inflación no garantiza por sí mismo el crecimiento y el bienestar de la sociedad, que es el verdadero objetivo que todo gobernante debe buscar para su economía.

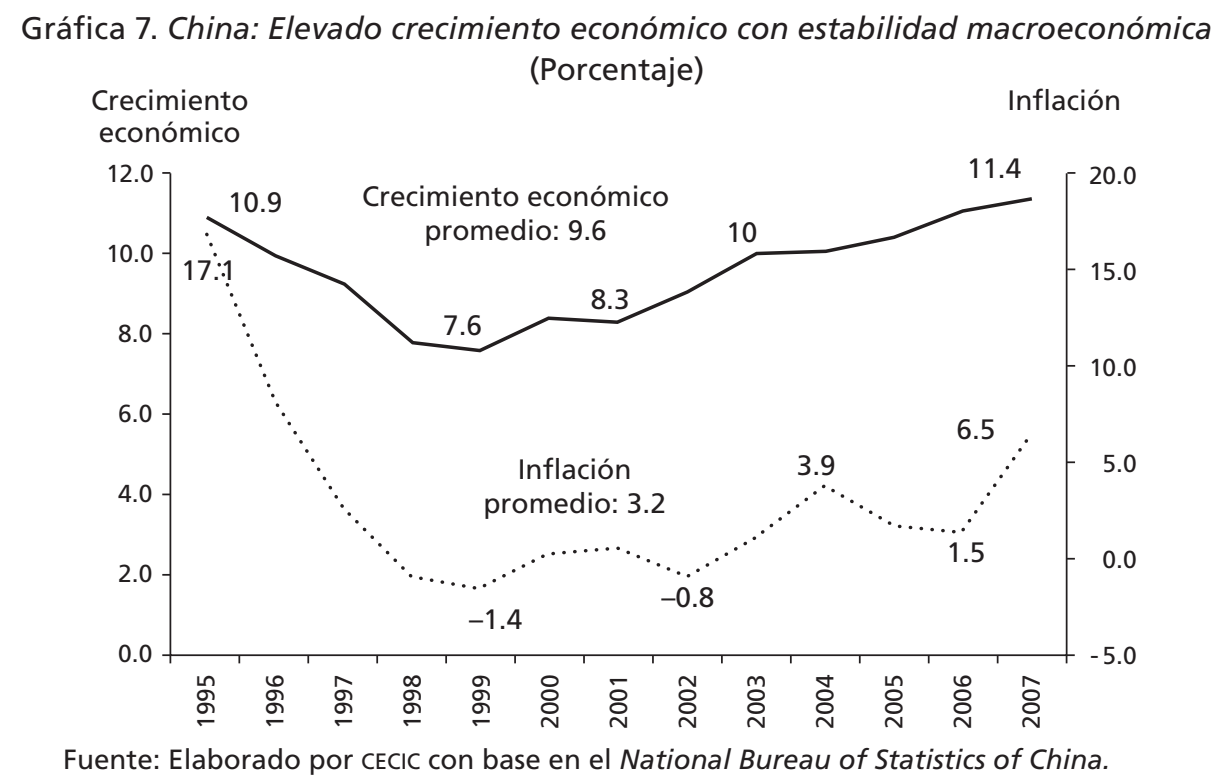


El arte del manejo macroeconómico se encuentra en alcanzar la tasa de crecimiento potencial de pleno empleo junto con una inflación baja de un dígito, como ha venido ocurriendo en China (véase gráfica 7). La tasa de crecimiento promedio del PIB de China en el periodo de 1995 a 2007 es de 9.6\%, mientras que el promedio de la inflación es de $3.2 \%$. Lo anterior evidencia que en la actual era de la globalización es posible crecer de manera sostenida bajo un contexto de estabilización.

En el caso de la economía mexicana se ha logrado reducir considerablemente la inflación, pero el costo ha sido alto y se manifiesta en un estancamiento económico y prácticamente nulo crecimiento (1.7\%) del PIB per cápita durante el periodo 1995-2007. Nuestro país salió de la crisis económica de 1995 y logró tasas de crecimiento cercanas a las de pleno empleo durante el periodo 19962000; no obstante, a partir de 2001 entró en un persistente estancamiento económico, acentuado desde 2007 a la fecha a consecuencia de la caída del dinamismo económico de los EUA y la actual crisis financiera global, que aún no toca fondo, pues la mayor parte de los expertos coinciden en que para el año 2009 se tendrán tasas de crecimiento económico inferiores a las de 2008.

Así pues, se plantea la necesidad de que en el modelo macroeconómico de México se incluya el objetivo de crecimiento económico junto con el de inflación reducida.

En el caso de Estados Unidos, la ley encarga al banco central lograr inflación baja y estable con crecimiento y empleo. Incluso en los planteamientos originales del mecanismo de inflation targeting ${ }^{1}$ adoptado por muchos países

\footnotetext{
${ }^{1}$ El mecanismo de objetivos de inflación (inflation targeting) fue fundado en Nueva Zelanda y puesto en funcionamiento en 1990, y debido a las bondades que este esquema permitió en cuanto al abatimiento de la inflación, fue adoptado progresivamente por muchos países. En el nuestro, el Banco de México en el año 2001 adoptó este esquema, con algunas variantes, y se hizo público en el texto del programa monetario para ese año. En su forma original, y acorde con la experiencia internacional, este esquema se finca en cuatro elementos fundamentales: antes de actuar se requiere identificar las causas de la inflación así como los requisitos para lograr su abatimiento; el gobierno debe establecer metas explícitas de inflación para el corto y mediano plazos; se debe evaluar continuamente la evolución de los indicadores financieros, a fin de identificar si las acciones de política monetaria van en el sentido correcto o si es necesario corregirlas, y se requiere hacer del conocimiento público los objetivos de inflación así como la manera en que se plantea alcanzar dichas metas inflacionarias. Junto con lo anterior, se plantean las condiciones necesarias para la instrumentación correcta de la política monetaria: autonomía del banco central entendida como el abandono de las prácticas del señoreaje financiero, credibilidad de la política monetaria (implica que la PM no esté supeditada al desempeño de la política fiscal) y buena coordinación entre las políticas fiscal y monetaria.
} 
Grafica 8. México: estancamiento estabilizador

(Tasas de crecimiento económico e inflación. Porcentaje)

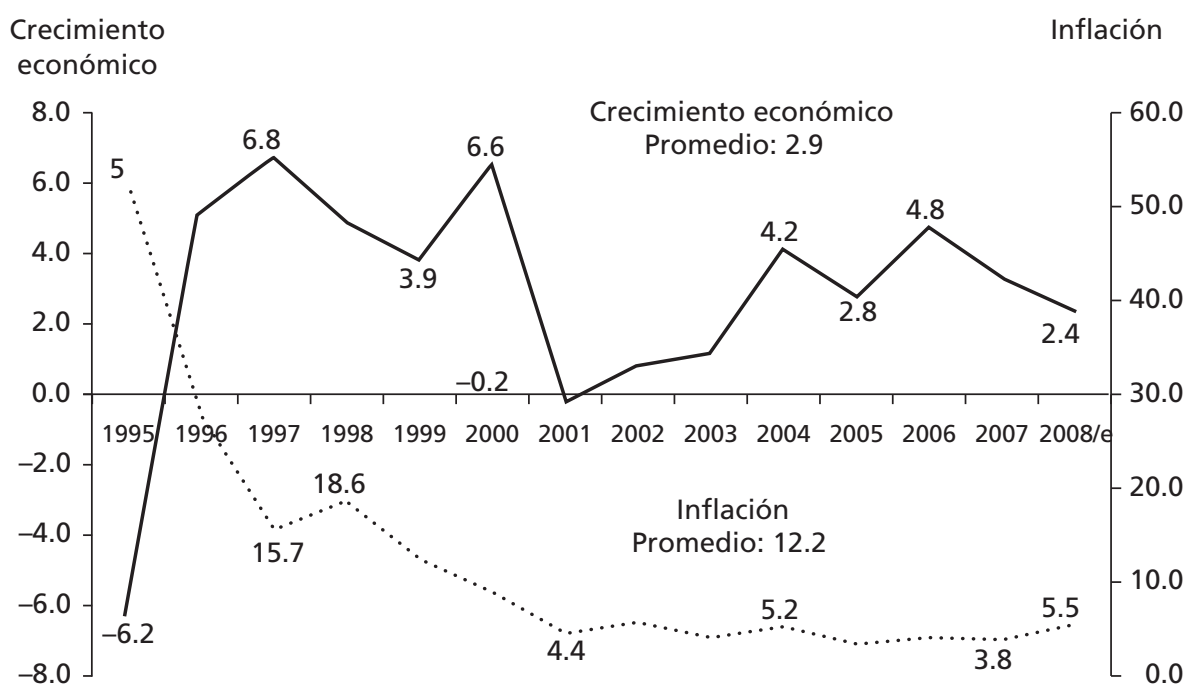

Fuente: Elaborado por CECIC con base en INEGI y Banco de México.

desde 1990, se hace hincapié en la necesidad de que exista una coordinación perfecta entre las políticas macroeconómicas fiscal y monetaria.

Por lo anterior es que se requiere un cambio en el esquema de objetivos de inflación o inflation targeting, debido a que éste es anacrónico e incongruente con la nueva economía global y sistémica, y no porque el esquema de inflation targeting sea incorrecto sino porque ya no existe una etapa de hiperinflación y se ha logrado, por lo contrario, una estabilidad de precios relativa en la década pasada, que se ha mantenido a pesar de la maxidevaluación reciente de 2009 de alrededor de $50 \%$ respecto a agosto de 2008 (de 10 a 15 pesos por dólar), lo que implica dar paso al objetivo de crecimiento y empleo con estabilidad. Hay que "cantar victoria sin bajar la guardia".

Se ha confundido la autonomía del Banco de México con la independencia de la política económica. Lo que significa la autonomía del banco central es el abandono de las prácticas del señoreaje financiero o financiamiento del gobierno federal con dinero primario a ultranza, y no el establecimiento de las metas de inflación de corto, mediano y largo plazos, dado que esta es una tarea que también compete al gobierno federal como parte de un programa integral de desarrollo económico. 
La evidencia no deja en claro si el Banxico logra identificar las verdaderas causas de la inflación y actúa en consecuencia. Aunque en la actualidad el Banxico hace uso del concepto de inflación subyacente ${ }^{2}$ para diferenciar entre la variación de precios de productos con diferente grado de volatilidad, en la práctica se observa que esta institución aplica la misma receta ante movimientos inflacionarios diferentes.

Por otra parte, se ha confundido la interdependencia de las políticas. Cuando se habla de la cooperación entre las políticas monetaria y fiscal, no se concibe supremacía de una política sobre otra. ${ }^{3}$ El verdadero arte del management consiste en lograr que los objetivos de la autoridad monetaria converjan con los del gobierno federal en cuanto al logro del fin común de la estabilidad con crecimiento competitivo, sustentable con pleno empleo y salario remunerativo.

Así, se debe reconocer que el modelo macroeconómico vigente ha sido exitoso en el abatimiento de la inflación, pues ésta se redujo de 159\% en 1987 a 9\% en el año 2000 y a $5 \%$ actualmente; sin embargo, el precio pagado ha sido muy alto.

Lo anterior plantea la conveniencia de redefinir la priorización de los objetivos del modelo macroeconómico imperante, para pasar del estancamiento estabilizador a un crecimiento competitivo con estabilidad de precios.

Por otra parte, ante la actual crisis financiera global el gobierno debe asumir un importante papel anticíclico, a fin de promover el crecimiento económico a partir de una sólida política pública de inversiones estratégicas en infraestructura, tecnología y otras áreas estratégicas. En este sentido, el pasado 9 de octubre de 2008 el presidente de México dio a conocer su Plan para Impulsar el Crecimiento y el Empleo y contrarrestar los efectos de la crisis financiera global, el cual consta de cinco grupos de acciones:

1. Ampliar el gasto público en infraestructura.

2. Implantar un programa de generación de empleos.

3. Implantar un programa de apoyo a las pequeñas y medianas empresas.

4. Construir una nueva refinería.

5. Implantar un esquema de desgravación arancelaria.

\footnotetext{
${ }^{2}$ La inflación subyacente se forma a partir de un subíndice del INPC representado por productos con bajo grado de volatilidad o que responden a la situación real de la dinámica económica nacional, más que a perturbaciones exógenas.

${ }^{3}$ Como, al parecer, concibe el gobernador del Banco de México, cuando señala que "para alcanzar una estabilidad de precios permanente es necesario que las políticas del gobierno federal sean compatibles con la política monetaria” (Ortiz, 2001, p. 12).
} 
En conjunto, se estima que la inversión adicional para 2009 sea de 53 mil millones de pesos (alrededor de 1\% del PIB). Si bien se trata de un plan anticíclico del gobierno federal, a estas acciones se debe sumar un fondo para fomentar el desarrollo tecnológico y científico de nuestro país para no rezagarnos en materia de competitividad.

\section{COMENTARIO FINAL}

La crisis económica y financiera global de 2008-2009 continúa inconclusa, así como el programa de rescate bancario, principalmente de Estados Unidos, y por tanto se sigue viviendo un escenario de recesión e incertidumbre en la economía internacional. Sin embargo, de lo que no hay duda es de su gran impacto en la recesión mundial que ya afectó a América Latina, en donde las perspectivas de una reactivación económica se aplazarán hasta 2010.

Ante este panorama, el impacto en la economía mexicana, tanto por la crisis global como en especial por la de los Estados Unidos, se ha manifestado en las exportaciones en general y en particular en las industrias automotriz y maquiladora, así como en el envío de remesas y el propio capital financiero, que se ha retraído tanto en el mercado de valores como en la inversión extranjera directa. En este contexto, la crisis devaluatoria que atraviesa México, con una maxidevaluación de 50\% (de octubre de 2008 a marzo de 2009) complica el escenario macroeconómico, ya que si bien corrige en parte el problema crónico de la apreciación cambiaria no lo hace de la mejor manera, pues siempre un desliz gradual en el marco del régimen de flotación administrada que hubiera alineado el tipo de cambio nominal con el tipo de cambio real competitivo hubiese sido más benéfico para el país.

En el presente ensayo se ha intentado dejar claro que el problema de estancamiento y pérdida de competitividad de la economía mexicana tiene como fondo el modelo de apertura macroestabilizador que se ha aplicado en las décadas pasadas y que se complica por la crisis financiera, la recesión global y la maxidevaluación de 2009, pero que no son la causa de lo que hemos llamado el estancamiento estabilizador anticompetitivo de la economía mexicana. 


\section{REFERENCIAS BIBLIOGRÁFICAS}

Ai Camp, Roderic (1997), “Tecnocracia a la mexicana, ¿antecedente a la democracia?”, Pensamiento Iberoamericano, Madrid, núm. 30, pp.155-176.

Alí, M. M., y S. I. Greenbaum (1976), "Stabilization Policy Uncertainty and Instrument Proliferation", Economic Inquiry, núm. 14.

Banco Mundial, "El desencanto de la democracia".

Friedman, B. M. (1995), The Moral Consequences of Economic Growth, Knopf,

Izquierdo, R. (1995), Política hacendaria del desarrollo estabilizador, 1958-1970, México, Fondo de Cultura Económica,.

Krugman, P. (1988), Exchange Rate Instability, MIT Press.

- (1995), Currencies and Crises, Massachusetts Institute of Technology Press.

Lederman, Daniel, William F. Maloney, y Luis Servén (2005), Lecciones del TLCAN para América Latina y el Caribe, Banco Mundial y Alfaomega, Colombiana.

Montecinos, Verónica (1997), "Introducción: ambigüedades y paradojas del poder tecnocrático en América Latina", Pensamiento Iberoamericano, Madrid, núm. 30.

Mundell, Robert A. (1962), "The Appropriate Use of Monetary and Fiscal Policy for Internal and External Stability", IMF Staff Papers, vol. 9, pp. 70-79.

— Robert A. (1995), "Stabilization and Liberalization Policies in semi-Open Economies", en Edwards Sebastian (ed.), Capital Controls, Exchange Rates and Monetary Policy in the World Economy, Cambridge, Massachusetts Institute of Technology.

Ocampo, J. A. (2004), “Latin America’s Growth and Equity Frustrations During Structural Reforms", Journal of Economic Perspectives, Vol. 18, núm. 2, primavera.

_ (2007), "La macroeconomía de la bonanza económica latinoamericana", Revista de la Cepal, Santiago de Chile, núm. 93, diciembre.

_ (2008), "The Tragedy of Current Latin American Monetary Policy", Latin America EconoMonitor, 1 de mayo.

Ortiz Mena, A. C., El desarrollo estabilizador: reflexiones sobre una época, México, Fondo de Cultura Económica.

Ortiz, Guillermo (2001), "La política monetaria: el esquema de objetivos de inflación y la disminución de la incertidumbre", en LXIV Convención Bancaria Globalización y Desarrollo Económico.

Ramos de Villarreal, R. (2000), Objetivos e instrumentos de política económica: una aplicación a México, México, Fondo de Cultura Económica.

Rodrik, D. (2008), "The Real Exchange Rate and Economic Growth", http://ksghome. harvard.edu/ drodrik/RER and growth.pdf 
Rogoff, Kenneth (2008), "El reto de los bancos centrales", El País, Madrid, 21 de septiembre, http://www.elpais.com/articulo/semana/reto/bancos/centrales/elpepuec oneg/20080921elpneglse_19/Tes/

Salinas de Gortari, C. (2008), La década perdida: 1995-2006. Neoliberalismo y populismo en México, México, Ed. Debate.

Stiglitz, Joseph E., José Antonio Ocampo, Shari Spiegel, Ricardo Ffrench-Davis y Deepak Nayyar (2006), Stability with Growth: Macroeconomics, Liberalization and Development, Oxford University Press.

Tinbergen, J. (1952), On the Theory of Economic Policy, Amsterdam, North-Holland.

Turnovsky, S. J. (1977), Macroeconomic Analysis and Stabilization Policy, Cambridge University Press, Londres, Nueva York, Melbourne.

Villarreal, R. (1983), La contrarrevolución monetarista: Teoría, política económica e ideología del neoliberalismo, México, Océano.

(2005), Industrialización, competitividad y desequilibrio externo en México: Un enfoque macroindustrial y financiero (1929-2010), México, Fondo de Cultura Económica, 5a. edición.

Williamson, J., (1994), The Political Economy of Policy Reform, Institute for International Economics. 
